\title{
SSynthesis
}

International Scientific Conference of IT and Business-Related Research

\section{INTERAKCIJA KAO DIJALOG IZMEĐU ČOVEKA I RAČUNARA}

\author{
INTERACTION AS A DIALOGUE BETWEEN HUMAN AND COMPUTER \\ Dragan Cvetković ${ }^{1}$, Dragan Marković 1 , Duško Radaković 2 , Srđan Trajković 2 \\ ${ }^{1}$ Univerzitet Singidunum, Danijelova 32, Beograd, Srbija, \\ ${ }^{2}$ Visoka škola strukovnih studija- Beogradska politehnika, Katarine Ambrozić 7, Beograd, Srbija
}

\begin{abstract}
Apstrakt:
Dijalog između korisnika i sistema u mnogome zavisi od stila ili vrste interfejsa. Interakcija se odvija u okviru socijalnog i organizacionog konteksta, koji utiču kako na korisnika, tako i na sistem. Interakcija može da se posmatra kao dijalog između čoveka i/ili korisnika i računara. Trebalo bi napomenuti da izbor stila interfejsa može da ima ogroman uticaj na prirodu ovog dijaloga. U ovom radu će biti reči o najčešćim stilovima interfejsa sa posebnim osvrtom na različite efekte koje oni imaju na interakciju.

Postoji veliki broj zajedničkih stilova interfejsa uključujući komandnu liniju unutar interfejsa, menije, prirodni jezik, dijaloge sa upitima, pitanjima i odgovorima, forme za popunjavanje i tabelarni proračun/ prikaz, WIMP interfejs, pozicioniranje i klik na dugme i trodimenzionalne interfejse.
\end{abstract}

\section{Ključne reči:}

Interfejs, interakcija, WIMP, GUI, dizajn.

\section{UVOD}

Postoji više načina na koji korisnik može da komunicira sa računarskim sistemom. Jedan ekstreman način je paketni ulaz (batch input), u kojem korisnik pruža sve informacije računaru odjednom i ostavlja računar da izvrši zadatak. Ovaj pristup podrazumeva interakciju između korisnika i računara, ali ne podržava dobro zadatke. Na drugom kraju su visoko interaktivni ulazni uređaji i paradigme, kao što su direktna manipulacija i primena virtualne realnosti. U ovom slučaju korisnik konstantno obezbeđuje instrukcije i primanje povratnih informacija. To su vrste interaktivnog sistema o kojima čovek razmišlja.

U ovom radu će se razmatrati komunikacija između korisnika i računarskog sistema - interakcija. Obratiće se pažnja na neke modele interakcije, koji omogućavaju da se identifikuju i procene komponente interakcije, kao i na fizičke, socijalne i organizacione karaktersitike koje definišu određeni kontekst. Takođe, ispitaće se neki od različitih stilova interakcije koji se koriste, što bi trebalo da navede na razmišljanje o tome kako dobro ti stilovi podržavaju korisnika.

Interakcija može da se posmatra kao dijalog između korisnika i računara. Izbor stila interfejsa može da ima dubok uticaj na prirodu ovog dijaloga. U ovom delu će biti reči o najčešćim stilovima interfejsa i obratiće se pažnja na različite efekte, koji

\section{Abstract:}

The dialogue between the user and the system is greatly affected by the choice of the style or the interface itself. The interaction takes place within the social and organizational context, which affects both the users and the system. The interaction can be viewed as a dialogue between humans (users) and computers. It should be noted that the choice of interface style can have a profound impact on the nature of the dialogue. The authors shall discuss the most common styles of interface with an emphasis on their various effects on the interaction. There is a number of common interface styles including command line interface, menus, natural language, dialogues with queries, questions and answers, forms to fill out and spreadsheet/presentation, WIMP interface, positioning and click on the button and 3D interfaces.

\section{Key words:}

Interface, interaction, WIMP, GUI, design.

ovi imaju na interakcije. Postoji veliki broj zajedničkih stilova interfejsa uključujući:

- komandnu liniju unutar interfejsa,

- menije,

- prirodni jezik,

- dijaloge sa upitima, pitanjima i odgovorima,

- forme za popune i tabelarni proračun/prikaz,

- WIMP interfejs,

- pozicioniranje i klik na dugme, i

- trodimenzionalne interfejse.

\section{KOMANDNA LINIJA UNUTAR INTERFEJSA}

Interfejs sa komandnim linijama (slika 1) je bio prvi interaktivni stil dijaloga, koji se najčešće koristio, i uprkos dostupnosti interfejsa sa menijima, i dalje je u širokoj upotrebi. On obezbeđuje izražavanja uputstava direktno računaru, koristeći funkcijske tastera, pojedinačne karaktere, skraćenice ili komande sastavljene od celih reči. U nekim sistemima komandna linija je jedini način komunikacije sa sistemom. Danas se interfejs sa komandnim linijama tretira kao dopunski interfejs, u odnosu na interfejs sa menijima, pružajući ubrzani pristup funkcionalnostima sistema za iskusne korisnike. 
Interfejsi sa komandnim linijama su izuzetno moćni, jer nude direktan pristup sistemskoj funkcionalnosti, za razliku od hijerarhijske prirode menija, a mogu i da primene niz alata, kako bi pristupili istim podacima. Oni su, takođe, fleksibilni komande često imaju niz opcija ili parametara koji će doprineti različitom ponašanju, na neki način, i mogu da se primene na više objekata odjednom, što je dobro za zadatke koji se ponavljaju. Međutim, ova fleksibilnost i snaga sa sobom donose teškoće u korišćenju i učenju. Komande moraju da se pamte, jer nema pokazatelja (oznaka) u komandnoj liniji da ukažu koja je komanda potrebna. Oni su, zbog toga, bolji za eksperte, nego za početnike. Ovaj problem može da se malo ublaži pomoću doslednih i smislenih komandi i skraćenica. Komande, koje se koriste, trebalo bi da budu terminološki unutar rečnika korisnika, a ne na tehničkom nivou. Nažalost, komande su često nejasne i variraju širom sistema, izazivaju zabunu korisniku i povećavaju potrebno vreme za njihovo učenje.

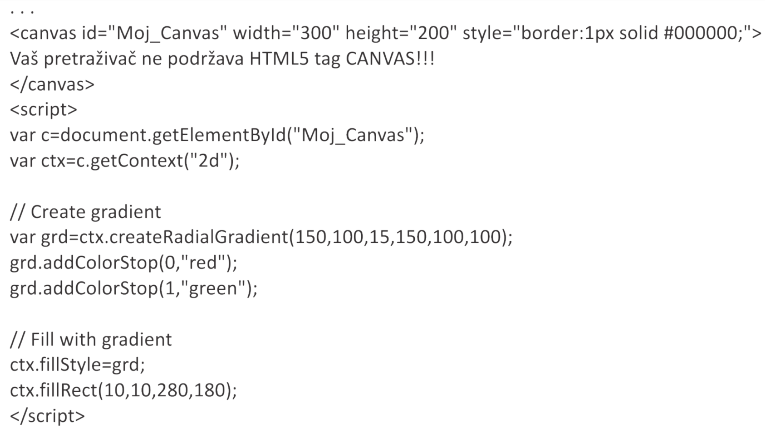

Slika 1. Interfejs sa komandnim linijama

\section{MENIJI}

U interfejsu sa menijima, raspoložive opcije su na raspolaganju korisniku i prikazuju se na ekranu, a biraju se pomoću miša ili numeričkih tastera ili abecede. Pošto su opcije vidljive, manje su zahtevne za korisnika, jer se oslanjaju na prepoznavanje, a ne na pamćenje i pozivanje. Međutim, meniji sa opcijama bi i dalje trebalo da bude smisleni i logički grupisani, kako bi pomogli korisniku oko prepoznavanja želeljene komande. Često su meniji hijerarhijski uređeni i potrebna opcija nije dostupna na gornjem sloju hijerarhije. Grupisanje i imenovanje menija sa opcijama su određena vrsta pokazatelja za korisnika da pronađu željenu opciju. Takvi sistemi mogu da budu čisto tekstualni, sa menijem opcija, gde su opcije predstavljene kao numerisane stavke (slika 2); mogu da imaju grafičku komponentu u kojoj se pojavljuje meni, u okviru pravougaone oblasti, a izbor opcije može da se obavi kucanjem početnog slova željene selekcije, ili unosom pridruženog (povezanog) broja, ili pomeranjem kursora oko menija pomoću tastera sa strelicama. Ovo je ograničena forma kompletnog WIMP sistema.

Detalji plaćanja
Treba definisati način plaćanja (izabrati broj):
1. Gotov novac (keš)
2. Ček
3. Kreditna kartica
4. Debitna kartica
5. Faktura
8. Prekid transakcije

Slika 2. Interfejs sa menijima

\section{PRIRODNI JEZIK}

Verovatno je najatraktivniji način za komunikaciju sa računarom, barem na prvi pogled, korišćenjem prirodnog jezika. Korisnici, koji ne mogu da se sete komande ili su se "izgubili" u hijerarhiji menija, mogli bi da komuniciraju sa računarom koji je u stanju da razume uputstva izražena svakodnevnim rečima! Razumevanje prirodnog jezika, i govora i pisanog ulaza, je predmet od velikog interesa i istraživanja. Nažalost, dvosmislenost prirodnog jezika ga čini veoma teškim za razumevanje od strane računara. Jezik je dvosmislen na više nivoa.

Čak i ako je struktura rečenica jasna, može da se nađe dvosmislenost u značenju reči koje se koriste. Na primer, reč "teren" može da se odnosi na sportsko polje ili, kolokvijalno, na neku teritoriju. Ljudi se često oslanjaju na kontekst i njihovo opšte znanje kako bi sredili ove nejasnoće. Ove informacije je teško obezbediti računaru. Upotreba zamenica i relativnih termina još više povećavaju dvosmislenost, što dodatno komplikuje stvari.

Imajući u vidu ove probleme, malo je verovatno da će interfejs sa primenom opšte prirodnog jezika biti na raspolaganju u dogledno vreme. Međutim, mogu da se izgrade sistemi koji su u stanju da shvate ograničene podskupove jezika. Za poznate i ograničene domene, sistem može da obezbedi dovoljno informacija za dvosmislene uslove. Važno je, kada su u pitanju interfejsi koji koriste prirodni jezik u ovoj ograničenoj formi, da je korisnik svestan ograničenja sistema i da ne očekuje previše razumevanja.

Trebalo bi napomenuti da je upotreba prirodnog jezika u ograničenim domenima relativno uspešna, ali je diskutabilno da li to zaista može da se nazove prirodan jezik. Korisnik i dalje mora da nauči koje fraze računar razume i može da postane frustriran, ako očekuje previše. Međutim, nije jasno ni koliko bi interfejs sa primenom opšteg prirodnog jezika, bio koristan. Jezik je po prirodi neodređen i neprecizan, a to mu daje fleksibilnost i omogućava kreativnost u izrazu. Računari, sa druge strane, zahtevaju precizna uputstva. Ako korisnik ima odrešene ruke, da li bi mogao da opiše njegove zahteve računaru dovoljno precizno, kako bi dobio određeni odgovor? Ako može da koristi prirodan jezik u potpunosti, ko mu garantuje da njegove komande neće da se "prevedu" na ograničen podskup opšteg prirodnog jezika?

\section{DIJALOZI SA UPITIMA, PITANJIMA I ODGOVORIMA}

Dijalog sa pitanjima i odgovorima je jednostavan mehanizam za pružanje ulaza aplikaciji u određenom domenu. Korisniku je postavljen niz pitanja (uglavnom sa odgovorima da ili ne, višestrukim izborom, odnosno kodovima) i tako je korisnik vođen kroz interakciju, korak po korak. Primer za ovo bi bio Web upitnik.

Ovi interfejsi se lako uče i koriste, ali imaju ograničenu funkcionalnost i moć. Kao takvi, oni su zaista odgovarajući za ograničene oblasti (naročito informacione sisteme) i za početnike i povremene korisnike.

Dijalog sa upitima, sa druge strane, se koristi za izgradnju upita, pomoću programskih jezika koji su specijalizovani za upite, (query languages), da bi se preuzeli podaci iz baze podataka. Oni koriste fraze u stilu prirodnog jezika, ali zahtevaju specifičnu sintaksu, kao i poznavanje strukture baze podataka. Upiti obično zahtevaju od korisnika da navede atribut ili atribute po kojima bi trebalo pretražiti bazu podataka, kao i željene atribute koje bi trebalo prikazati. To je jednostavno, gde postoji jedan atribut, ali postaje složenija priča kada je uključeno više atributa. Većina jezika specijalizovanih za upite ne pruža direktnu potvrdu onoga 
što je traženo, tako da jedinu validaciju koju ima korisnik je rezultat pretrage. Efikasna upotreba jezika specijalizovanih za upite, očigledno, zahteva neko iskustvo. Specijalizovani primer za ovo je veb pretraživač.

\section{FORME ZA POPUNJAVANJE I TABELARNI PRORAČUN}

Interfejsi sa formama za popunjavanje se, pre svega, koriste za unos podataka, ali takođe mogu da budu korisni u aplikacijama za preuzimanje podataka. Korisniku je predstavljen ekran koji podseća na papirni obrazac, sa poljima za popunjavanje (slika 3). Često se prikazana forma zasniva na stvarnom obliku sa kojim je korisnik upoznat, što čini interfejs lakšim za korišćenje. Korisnik radi kroz formu, popunjavanjem odgovarajućih vrednosti. Na ovaj način podaci ulaze u primenu sa ispravnog mesta. Kroz većinu interfejsa sa formama za popunjavanje je omogućeno lako kretanje i omogućeno je da neka polja mogu da ostanu prazna. Oni, takođe, zahtevaju i potencijalnu korekciju objekata, ako se korisnici predomisle ili ako se napravi greška o vrednostima koje pripadaju svakom polju. Unos podataka kroz dijalog je koristan, pre svega, za unos podataka, a i lak je za učenje i upotrebu, posebno za nove korisnike. Međutim, pod pretpostavkom da je reč o dizajnu koji omogućava fleksibilan unos, interfejsi sa formama za popunjavanje su, takođe, pogodni za iskusnije korisnike.

\begin{tabular}{|c|c|}
\hline \multicolumn{2}{|c|}{ Unos osnovnih podataka za novog studenta } \\
\hline Ime: & Broj indeksa: \\
\hline Aleksandar & 2014220022 \\
\hline Prezime: & Datum rođenja: \\
\hline Marković & 05.08.1995. \\
\hline Studijski program: & \\
\hline Informatika i računarstvo & \\
\hline SNIMI & OTKAŽI \\
\hline
\end{tabular}

Slika 3. Tipični interfejs sa formama za popunjavanje ("klasični” formulari)

Tabelarni proračuni (spreadsheets) unutar određenih programa predstavljaju sofisticirane varijacije formi za popune. Tabela obuhvata mrežu ćelija, od kojih svaka može da sadrži vrednost ili formulu (slika 4).

\begin{tabular}{|c|c|c|c|c|c|}
\hline \multicolumn{6}{|c|}{ Promet na računu } \\
\hline Datum & Opis & Oznaka & Ulaz & Izlaz & Ukupno \\
\hline 10.03 .2015 . & Softverski paket 1-235467 & SP-01-235467 & $1.156,22$ & & $1.156,22$ \\
\hline 11.03.2015. & Softverski paket $2-224345$ & SP-02-224345 & & 801,34 & 354,88 \\
\hline 12.03.2015. & Softverski paket 3-887564 & SP-03-887564 & 2 & & 1.342 \\
\hline 13.03.2015. & Softverski paket 4 - 099878 & SP-04-099878 & & 672,98 & 669,02 \\
\hline 16.03 .2 & Softverski paket 5 - 110921 & SP-05-110921 & $2.346,34$ & & $3.015,36$ \\
\hline 16.03 .2 & Softverski paket 6 - 445367 & SP-06-4C & & $1.245,76$ & $1.769,60$ \\
\hline 17.03.2015 & Softverski paket 7 - 444444 & SP-07-444444 & & 672,98 & $1.096,62$ \\
\hline 17.03.2015. & Softverski paket $8-888888$ & SP-08-888888 & & 346,34 & 732,28 \\
\hline 17.03.2015 & Softverski paket 9 - 123455 & SP-09-123455 & $1.701,01$ & & $2.433,29$ \\
\hline \multicolumn{5}{|c|}{ Presek na dan 17.03.2015. godine } & $2.433,29$ \\
\hline
\end{tabular}

Slika 4. Tipičan prikaz programa za tabelarni proračun

Formula može uključiti vrednosti drugih ćelija; na primer, ukupna vrednost svih ćelija u toj koloni. Korisnik može da unese i menja vrednosti formula u bilo kom redosledu, a sistem će da održava konzistentnost među prikazanim vrednostima, osiguravajući da se sve formule poštuju. Korisnik može da ma- nipuliše vrednostima kako bi video efekte promene različitih parametara. Programi za tabelarni proračun su atraktivni medijum za interakciju - korisnik može slobodno da manipuliše vrednostima po volji i razlika između ulaza i izlaza je "zamagljena”, što čini interfejs fleksibilnijim i prirodnijim.

\section{POZICIONIRANJE I KLIK NA DUGME}

U većini multimedijalnih sistema i veb pretraživača, gotovo sve akcije se preduzimaju samo jednim klikom na taster miša. Na primer, korisnik može da ukaže na grad na mapi i kada klikne da se otvori prozor, pokazujući turističke informacije o gradu. Može da ukaže na reči u nekom tekstu, a kada klikne mišem da vidi definiciju reči. Može da ukaže na prepoznatljivu ikonicu i kada klikne na nju da se izvrši neka radnja.

Ovaj stil interfejsa sa primenjenom tehnikom tačka-i-klik je, očigledno, u tesnoj vezi sa WIMP stilom. Jasno je preklapanje u korišćenju tastera (dugmadi), ali može da sadrži i druge elemente WIMP interfejsa. Međutim, filozofija je jednostavnija i blisko povezana sa idejama hiperteksta (hypertext, na primer HTML). Pored toga, stil tačka-i-klik nije "vezan” za interfejse koji su bazirani na upotrebi miša, a takođe, koristi se intenzivno kod informacionih sistema sa displejima osetljivim na dodir. U ovom slučaju, često se kombinuje sa interfejsom sa menijima.

Stil tačka-i-klik je popularizovan od strane WWW (World Wide Web) stranica, koje uključuju sve gore navedene vrste tačka-i-klik navigacija - istaknute reči, mape i tasteri sa ikonicama.

\section{TRODIMENZIONALNI INTERFEJSI}

Na tržištu je sve veća potražnja za trodimenzionalnim efektima u korisničkim interfejsima, što dovodi do pojave trodimenzionalnih interfejsa. Najočigledniji primer je virtualna realnost (VR), ali VR je samo deo 3D tehnika koje stoje na raspolaganju dizajneru i/ili projektantu interfejsa.

Najjednostavnija tehnika je viđena kod WIMP interfejsa, gde su elementi, kao tasteri i barovi, “dobili” 3D izgled pomoću senčenja, dajući izgled elementima kao da su izvajani od kamena. Po nepisanoj konvenciji, takvi interfejsi imaju izvor svetlosti u svom gornjem desnom uglu. Kada se senčenje koristi racionalno, izabrana područja su lako prepoznatljiva i mogu da se iskoriste za isticanje aktivnih oblasti (slika 5). Nažalost, kod nekih interfejsa je očigledna neselektivna primena skulpturalnih efekata (gde god se pojavi tekst, granični okvir ili meni), pa se osećaj diferencijacije gubi.

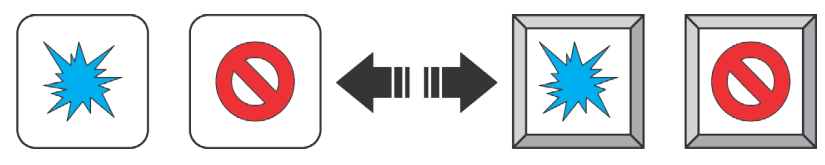

Slika 5. Tasteri sa 3D "prikazom"

Složenija tehnika koristi interfejse sa $3 \mathrm{D}$ radnim prostorima. Predmeti, prikazani u takvim sistemima, su obično ravni, ali se prikazuju u perspektivi, tako da korisnik ima osećaj dubine i može da "definiše" koji je predmet bliži, a koji dalji (slika 6). Trebalo bi obratiti pažnju na to kako veličina, svetlo i perspektiva pružaju osećaj udaljenosti. Očigledno je, takođe, da dalji objekti zauzimaju manje prostora na ekranu. Trodimenzionalni radni prostori mogu korisniku da obezbede dodatni prostor, ali na prirodniji način. 


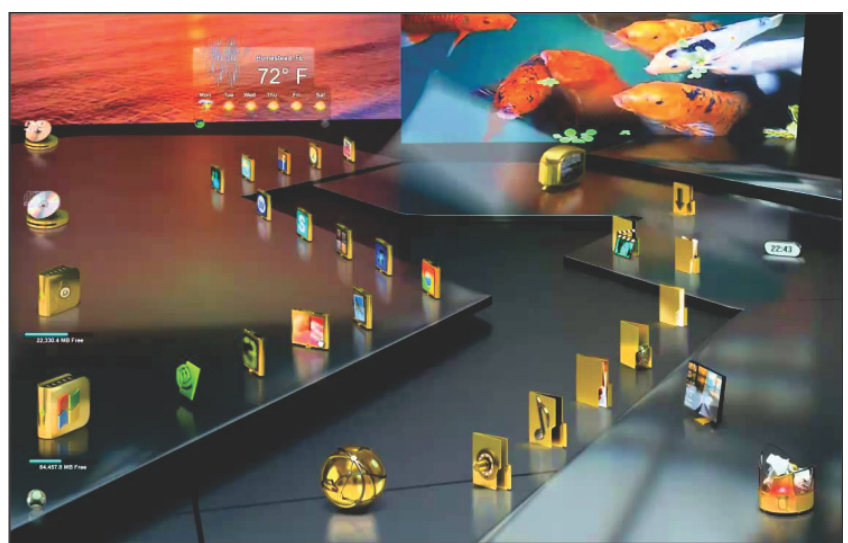

Slika 6. Upotrebom 3D-a se dolazi do dodatnog prostora

Konačno, postoje VR i informacioni sistemi za vizuelizaciju, gde korisnik može da se kreće okolo u simuliranom 3D svetu. Ovi mehanizmi se preklapaju sa drugim stilovima interakcije, posebno korišćenje skulpturalnih elemenata u WIMP interfejsimaa. Međutim, postoji jasan način (stil) interakcije za 3D interfejse, koji "poziva" korisnika da koristi određene sposobnosti iz stvarnog sveta, i da ih prevede u elektronski svet. Početnici moraju da nauče da ovalni prostor, sa reči ili slikom u njemu, predstavlja dugme koje bi trebalo pritisnuti, a 3D taster kao da kaže "pritisni me". Kompletnije 3D okruženje će "pozvati" korisnika da se kreće unutar virtualnog okruženja, i to će korisnik da uradi, radije nego da statira i gleda kao posmatrač.

\section{WIMP INTERFEJS}

Trenutno, mnoga zajednička okruženja za interaktivno računarstvo se ogledaju kroz primenu WIMP interfejsa, koji se, često, jednostavno naziva sistem sa prozorima. Naziv WIMP je skraćenica za prozore, ikonice, menije i pokazivače (windows, icons, menus, pointers), a to je, ponekad, i skraćenica za prozore, ikonice, miševe i padajuće menije. Ovo je uobičajeni interfejs za većinu interaktivnih računarskih sistema koji su danas u upotrebi, posebno kod PC-a i desktop radnih stanica. Ovi interfejsi su uključeni u operativni sistem Microsoft Windows za personalne računare, MacOS za Apple Macintosh kompatibilne računare i u razne sisteme za UNIX.
Već su spomenute četiri ključne karakteristike WIMP interfejsa koji mu daju ime - Windows, Icons, Menus, Pointers. Tu su i mnoge dodatne interakcije objekata i tehnike, koje se obično koriste u WIMP interfejsima, neki su dizajnirani za specifične namene, a drugi za opšte. Većina ovih elemenata može da se vidi na slici 7.

Zajedno, svi ovi elementi WIMP interfejsa se nazivaju dodaci ili dodatne male aplikacije (widgets), a oni obuhvataju komplet alata (toolkit) za interakciju između korisnika i sistema. Tu će se otkriti da, iako većina modernih sistema sa prozorima obezbeđuje isti skup osnovnih dodataka, koji "izgledaju i osećaju” - kako se dodaci fizički prikazuju i kako korisnici mogu da komuniciraju sa njima da bi pristupili njihovim funkcionalnostima - sistemi sa prozorima i kompleti alata mogu drastično da se razlikuju.

Prozori (windows) su područja monitora koja se ponašaju kao da su nezavisni terminali sa sopstvenim pravima. Prozor može, obično, da sadrži tekst ili grafiku, a može da se pomera ili skalira. Na ekranu može da se prikaže više od jednog prozora odjednom, i na taj način je omogućeno da odvojeni zadaci budu vidljivi $\mathrm{u}$ isto vreme. Korisnici mogu da usmere svoju pažnju na različite prozore, jer su u stanju da se prebacuju sa jednog na drugi.

Pored ovoga, mogu da postoje posebna polja u uglovima prozora, koja omogućavaju promenu veličine, zatvaranje ili skaliranje prozora (slika 8 ).

Pored toga, neki sistemi omogućavaju prozore unutar prozora. Na primer, u Microsoft Office aplikacijama (Excel i Word), svaka aplikacija ima svoj prozor, a zatim i svaki dokument ima svoj prozor. Često je moguće da postoje različite politike rasporeda u okviru različitih prozora aplikacije.

Prozor može da bude zatvoren i izgubljen zauvek, ili može da bude "skupljen" (skaliran) do neke veoma smanjene prezentacije (zastupljenosti). Takva mala slika se koristi da predstavi zatvoren prozor, a ova prezentacija je poznata kao ikonica (icon). Dozvoljavajući primenu ikonica, mnogi prozori mogu da budu dostupni na ekranu u isto vreme, i spremni su da budu prošireni do njihove pune veličine klikom na ikonicu. Skupljanje prozora na njegovu ikonicu je poznato kao ikonofikacija prozora. Kada korisnik privremeno ne želi da prati određeni dijalog, on može da suspenduje taj dijalog ikonofikacijom prozora koji sadrži pomenuti dijalog.
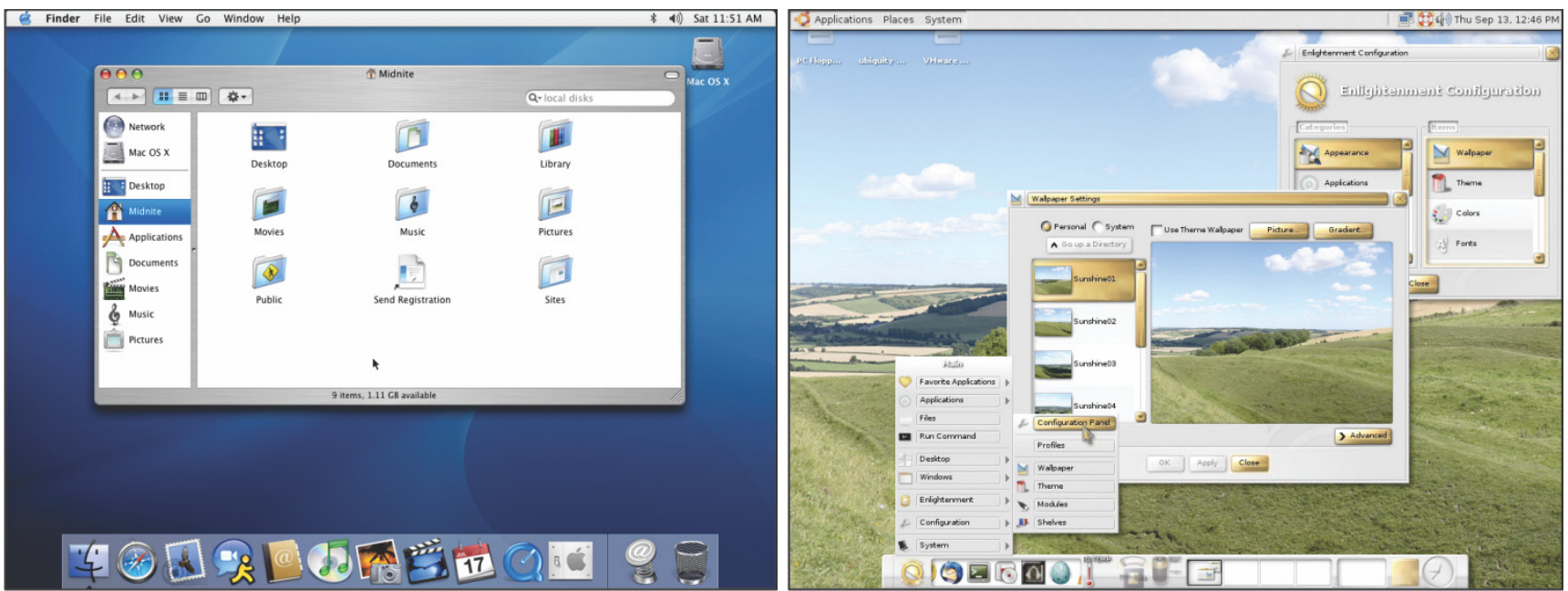

Slika 7. Elementi WIMP interfejsa 


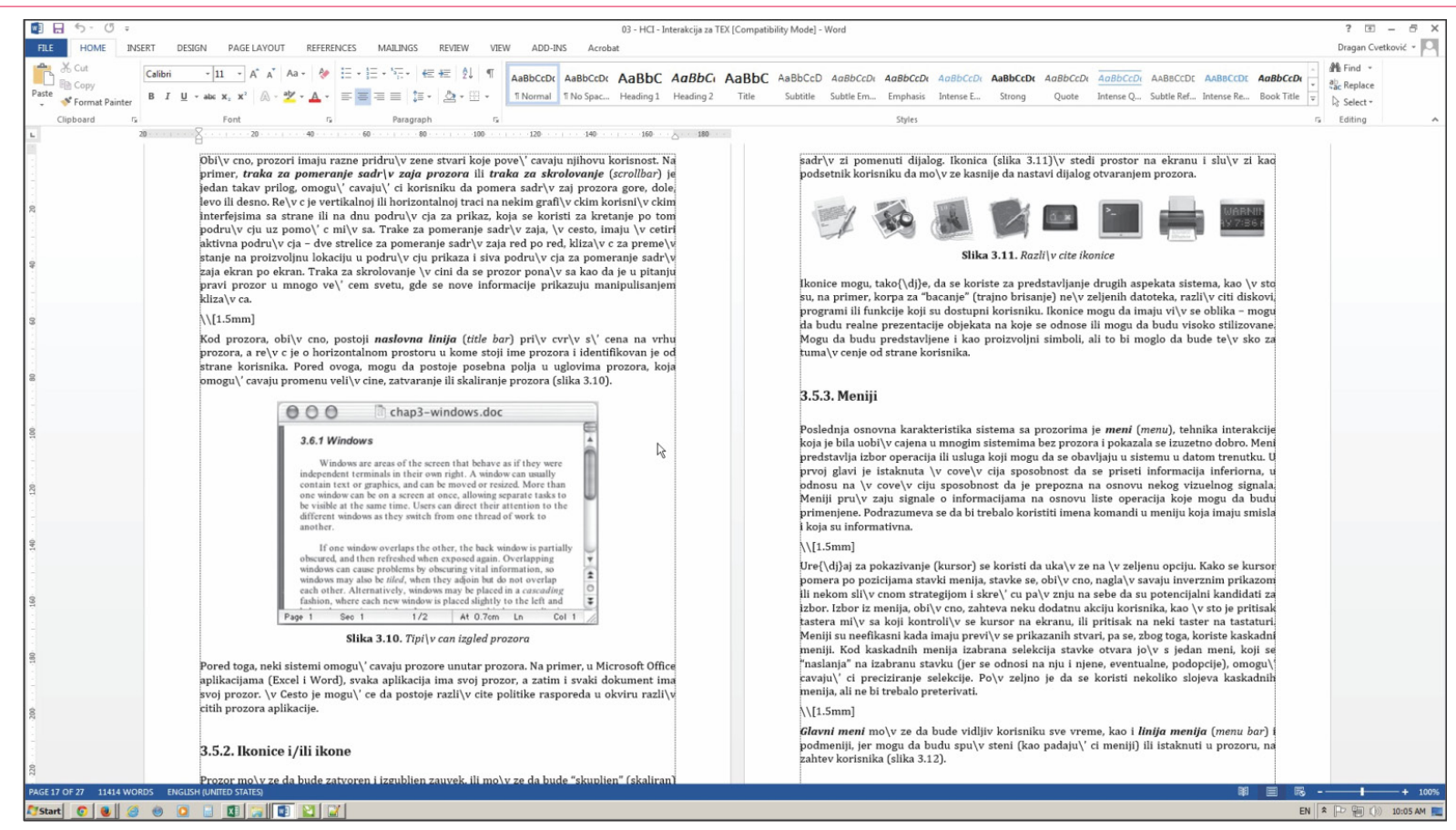

Slika 8. Tipičan izgled prozora

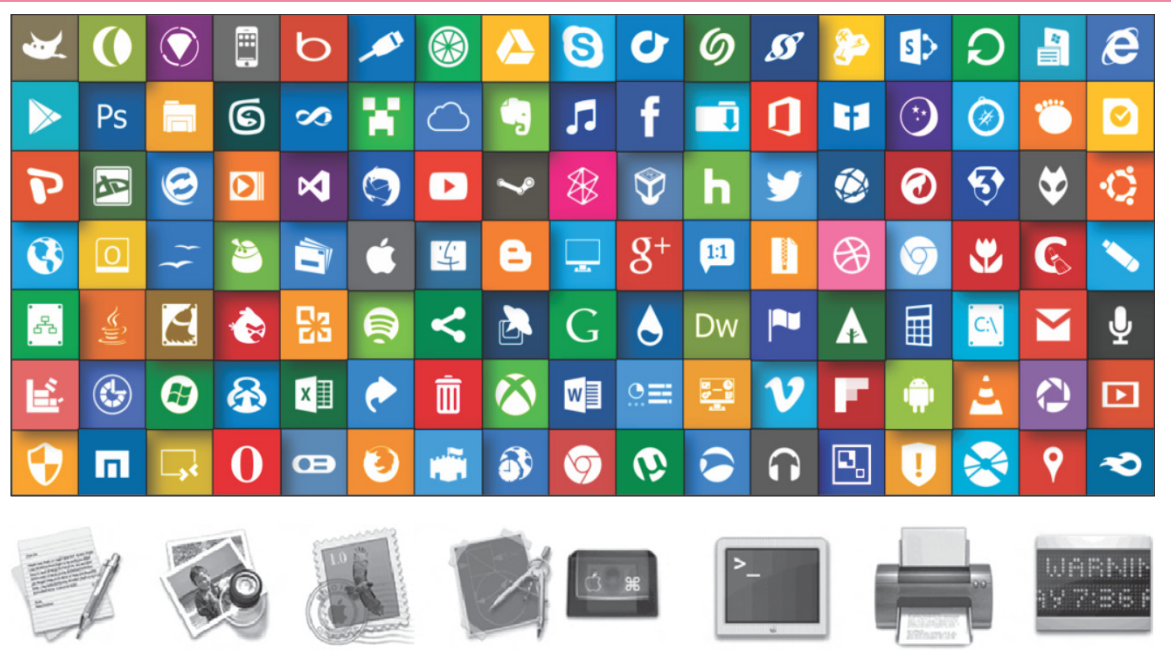

Slika 9. Različite ikonice

Ikonice mogu, takođe, da se koriste za predstavljanje drugih aspekata sistema, kao što su, na primer, korpa za "bacanje" (trajno brisanje) neželjenih datoteka, različiti diskovi, programi ili funkcije koji su dostupni korisniku. Ikonice mogu da imaju više oblika - mogu da budu realne prezentacije objekata na koje se odnose ili mogu da budu visoko stilizovane. Mogu da budu predstavljene i kao proizvoljni simboli, ali to bi moglo da bude teško za tumačenje od strane korisnika.

Poslednja osnovna karakteristika sistema sa prozorima je meni (menu), tehnika interakcije koja je bila uobičajena u mnogim sistemima bez prozora i pokazala se izuzetno dobro. Meni predstavlja izbor operacija ili usluga koje mogu da se obavljaju u sistemu u datom trenutku. Uređaj za pokazivanje (kursor) se koristi da ukaže na željenu opciju. Kako se kursor pomera po pozicijama stavki menija, stavke se, obično, naglašavaju inverznim prikazom ili nekom sličnom strategijom i skreću pažnju na sebe da su potencijalni kandidati za izbor. Izbor iz menija, obično, zahteva neku dodatnu akciju korisnika, kao što je pritisak tastera miša koji kontroliše kursor na ekranu, ili pritisak na neki taster na tastaturi. Meniji su neefikasni kada imaju previše prikazanih stvari, pa se zbog toga koriste kaskadni meniji.
Kod kaskadnih menija izabrana selekcija stavke otvara još jedan meni, koji se "naslanja" na izabranu stavku (jer se odnosi na nju i njene, eventualne, podopcije), omogućavajući preciziranje selekcije. Poželjno je da se koristi nekoliko slojeva kaskadnih menija, ali ne bi trebalo preterivati.

Glavni meni može da bude vidljiv korisniku sve vreme, kao i linija menija (menu bar) i podmeniji, jer mogu da budu spušteni (kao padajući meniji) ili istaknuti u prozoru, na zahtev korisnika (slika 10).

Glavni problemi sa menijima, uopšte, su stavke (opcije) koje stavke uključiti i kako ih grupisati. Ako se uključi previše stavki, meniji postaju predugački ili ima previše menija, dok grupisanje stvara probleme zbog toga što bi stavke, koje se odnose na istu temu, trebalo da budu smeštene pod isti naslov, a ipak mnoge stavke mogu da se grupišu pod više od jednog naslova. Kada je reč o padajućim menijima, naslov menija bi trebalo da bude definisan tako da odražava funkciju stavki menija, kao i funkcija stavki koje su grupisane u menijima. Ove grupacije bi trebalo da budu konzistentne kroz aplikacije, tako da korisnik može da prenese stečeno znanje u nove aplikacije. Opcije menija se ređaju po značaju i učestalosti upotrebe, 


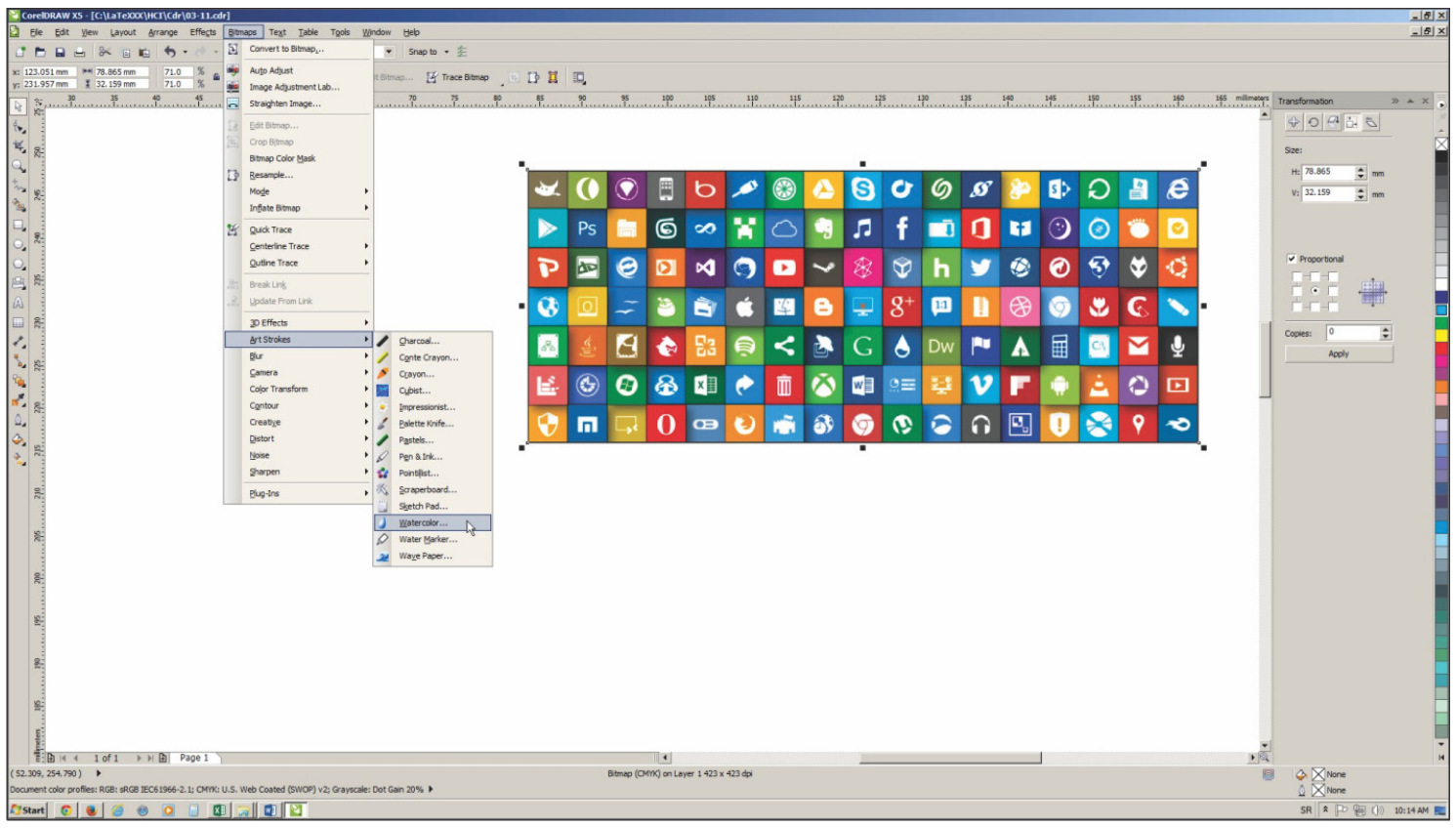

Slika 10. Padajući meni i podmeni

a funkcije, kao što su Save i Delete, bi trebalo držati odvojeno, kako bi se sprečio slučajan izbor pogrešne funkcije, sa potencijalno katastrofalnim posledicama.

Pokazivač je važna komponenta WIMP interfejsa, jer stil interakcije koji zahteva ovaj interfejs se mnogo oslanja na pokazivanje i selekcije objekata, kao što su ikonice. Miš predstavlja ulazni uređaj koji je sposoban da odradi takve zadatke, mada alternative su i džojstici i pokazivački uređaji sa kuglom. Korisnik je predstavljen pomoću kursora na ekranu koji je pod kontrolom ulaznog uređaja. Mnoštvo pokazivačkih kursora je prikazano na slici 11 .

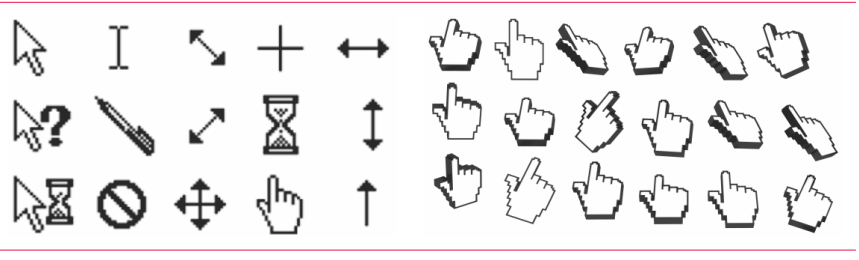

Slika 11. Različiti pokazivački kursori

Različiti oblici kursora se često koriste za razlikovanje režima; na primer, normalni pokazivač kursora može biti u obliku strelice koji se menja/pretvara u oblik krstića (končanice) kada se crta linija. Kursori, takođe, mogu da se koriste kako bi informisali korisnika o aktivnostima sistema; na primer, kursor u obliku peščanog sata ili digitalnog sata može da se prikazuje kada je sistem zauzet učitavanjem datoteka.

\section{ZAKLJUČAK}

Kada se gleda na interfejs, lako je korisniku da se fokusira na vizuelno odvojene celine (dugmad, tasteri, meniji, tekstualna područja), ali dinamika, način na koji interfejs reaguje na radnje korisnika, su manje očigledne. Razvoj i dizajn dijaloga se, u većini slučajeva, fokusira skoro u potpunosti na izbor i specifikacije odgovarajućih sekvenci akcija i odgovarajućih promena u stanju interfejsa. Međutim, to se obično ne koristi na finom nivou detalja i namerno ignoriše "semantički" stepen interfejsa; na primer, validacija numeričke informacije u sistemu je zasnovana na obrascima (formama).
Trebalo bi se podsetiti da je interaktivnost definisanje karakteristika interaktivnog sistema. Ovo može da se vidi u mnogim oblastima HCI (Human Computer Interaction). Na primer, prepoznavanje govora je na niskom nivou da bi se vršila transkripcija sa trake, ali u sistemu za rezervacije avio kompanija je prihvatljivo, sve dok sistem može pouzdano da prepozna odgovore da (yes) i ne (no) i dok može da reflektuje natrag svoje razumevanje onoga što je rečeno i da traži potvrdu. Ulaz u sistem na bazi govora je težak, ali interakcija zasnovana na govoru je lakša. Takođe, u oblasti vizualizacije informacija se došlo do sjajnih rezultata, a najuzbudljivije je to što korisnici mogu da komuniciraju sa vizualizovanim informacijama i objektima u realnom vremenu, da menjaju parametre i da vide efekat.

Interaktivnost je, takođe, ključna u određivanju "osećaja" WIMP okruženja. Svi WIMP sistemi imaju gotovo iste elemente - prozore, ikonice, menije, pokazivače, okvire za dijalog, dugmad, tastere, itd. Međutim, precizno ponašanje ovih elemenata se razlikuje i unutar jednog okruženja i između okruženja. $\mathrm{Na}$ primer, već je bilo reči o drugačijem ponašanju padajućih i ispadajućih menija. Oni izgledaju isto, ali ispadajući meniji mogu lakše da se pozovu slučajno. U stvari, meniji su glavna razlika između MacOS i Microsoft Windows okruženja; kod MacOS korisnik mora da zadrži miša pritisnutog tokom selekcije menija; dok u operativnom sistemu Windows korisnik može da klikne na liniju sa menijima i padajući meni se pojavljuje i ostaje tamo sve dok je opcija (stavka) izabrana ili je otkazana.

\section{LITERATURA}

Colborne, G. (2011). Simple and Usable Web, Mobile, and Interaction Design. SAD: New Riders.

Dix, A., Finlay, J., Abowd, G.D., \& Beale, R. (2004). HumanComputer Interaction. London, UK: Pearson Education Limited.

Lai, R. (2013). Digital Design Essentials: 100 Ways to Design Better Desktop, Web, and Mobile Interfaces. SAD: Rockport Publishers.

Lidwell, W., Holden, K., \& Butler, L. (2003). Universal Principles of Design:100 Ways to Enhance Usability, Influence Perception, Increase Appealm Make Better Design Decisions, and Teach through Design. SAD: Rockport Publishers 
Martin, B., \& Hanington, B. (2012). Universal Methods of Design: 100 Ways to Research Complex Problems, Develop Innovative Ideas, and Design Effective Solutions. Beverly, MA: Rockport Publishers.

Peters, D. (2014). Interface Design for Learning:Design Strategies for Learning Experiences. Berkeley,CA: New Riders

Rogers, Y., Sharp, H., \& Preece, J. (2014). Interaction Design: Beyond Human-Computer Interaction. New York, NY: John Wiley \& Sons.
Sears, A., \& Jacko, J.A. (2009.) The Human-Computer Interaction Handbook: Fundamentals, Evolving Technologies and Emerging Applications. Boca Raton: CRC Press.

Shneiderman, B., \& Plaisant, C. (2006.) Dizajniranje korisničkog interfejsa: Strategije za uspešnu interakciju ljudi i računara. Beograd: Računarski fakultet i CET. 